\title{
Correction to: Management of Pulmonary Arterial Hypertension
}

\author{
Jennalyn D. Mayeux ${ }^{1} \cdot$ Irene Z. Pan ${ }^{2} \cdot$ John Dechand ${ }^{2} \cdot$ Joshua A. Jacobs ${ }^{2} \cdot$ Tara L. Jones $^{3} \cdot$ Stephen H. McKellar ${ }^{4}$. \\ Emily Beck ${ }^{1} \cdot$ Nathan D. Hatton ${ }^{1} \cdot$ John J. Ryan ${ }^{3}$
}

Published online: 27 November 2020

(C) Springer Science+Business Media, LLC, part of Springer Nature 2020

\section{Correction to: Current Cardiovascular Risk Reports (2021) 15:2 https://doi.org/10.1007/s12170-020-00663-3}

The original article contained outdated Figs. 1, 2, 3 and 4.

Due to typesetting mistake, the new versions of the figures were missed.

The original version has been corrected.

Publisher's Note Springer Nature remains neutral with regard to jurisdictional claims in published maps and institutional affiliations.

The online version of the original article can be found at https://doi.org/ 10.1007/s12170-020-00663-3

John J. Ryan

john.ryan@hsc.utah.edu

1 Division of Pulmonary and Critical Care Medicine, Department of Medicine, University of Utah, Salt Lake City, UT 84132, USA

2 Department of Pharmacy, University of Utah Health, Salt Lake City, UT 84132, USA

3 Division of Cardiovascular Medicine, Department of Medicine, University of Utah, 30 North 1900 East, Room 4A100, Salt Lake City, UT 84132, USA

4 Division of Cardiothoracic Surgery, Department of Surgery, University of Utah, Salt Lake City, UT 84132, USA 